\title{
Anxiety following cardiac surgery - an important aspect of health status assessment
}

\author{
KATARZYNA NOWICKA-SAUER 1, 2, A, D-F, SEBASTIAN BETA2, a, в , ROBERT NOWAK², \\ KRZYSZTOF JARMOSZEWICZ2, D, F, ANDRZEJ MOLISZ1, C, SEBASTIAN BATKIEWICZ2, в, \\ AGATA PŁOTKOWSKA-BARANOWSKA ${ }^{3, \mathrm{~F}}$, JANUSZ SIEBERT ${ }^{1, \mathrm{E}}$ \\ ${ }^{1}$ Department of Family Medicine, Interuniversity Center for Cardiology, Medical University of Gdansk \\ ${ }^{2}$ Cardiac Surgery Department, Gdansk Cardiovascular Center \\ ${ }^{3}$ Anesthesiology and Intensive Care Department, Gdansk Cardiovascular Center
}

A - Study Design, B - Data Collection, C - Statistical Analysis, D - Data Interpretation, E - Manuscript Preparation, $\mathbf{F}$ - Literature Search, $\mathbf{G}$ - Funds Collection

Summary Background. Patient-Reported Outcomes (PROs), including psychological factors, have become an important aspect of both health research and clinical practice. Patients who have undergone cardiac surgery can constitute a large subgroup of the patients of a family physician. Postoperative distress has been observed in up to $40 \%$ of patients.

Objectives. The study aimed to evaluate anxiety levels among patients who had undergone cardiac surgery, and to explore the correlations between anxiety and depression and subjective health status.

Material and methods. The research group consisted of 70 patients (48 men, mean age: 65.9 years; \pm 8.5 ). The study was conducted during consultations three months after surgery. The Hospital Anxiety and Depression Scale (HADS), including question regarding suicidal thoughts, was used. A four-point Likert scale was used to evaluate subjective effectiveness of the surgery and the Visual Analogue Scale (VAS) was used to assess subjective health status.

Results. An increased level of anxiety was observed in 23 patients (32.9\%), and depression was seen in 12 (17.1\%). 13 patients $(18.6 \%)$ indicated that they had had suicidal thoughts. Patients with suicidal ideation had significantly higher level of anxiety. Significant positive correlations were noted between levels of anxiety and depression. Anxiety level correlated negatively with subjective health status and assessment of surgery effectiveness. No significant connections were observed between level of anxiety and sex, age, or the type of surgery.

Conclusions. 1. Increased levels of anxiety were observed in a significant percentage of patients who had undergone cardiac surgery. 2. Increased anxiety level is concomitant with depression, suicidal thoughts, and lower subjective health status assessment. 3. Health status assessment following cardiac surgery should also include the evaluation of mental health.

Key words: anxiety, depression, cardiac surgery, PROs, postoperative follow-up.

Fam Med Prim Care Rev 2016; 18(3): 317-320

\section{Background}

Patient-Reported Outcomes (PROs), including psychological factors, have become an important aspect of both scientific research and clinical practice [1]. The 2013 recommendations of the American Heart Association stress the importance of the patient's assessment of their health status [1]. One vital factor in the subjective assessment of health status is the patient's self-assessment of the symptoms they experience, their ability to function, their emotions, and their quality of life [1]. Other authors have also pointed out that health status self-assessment should be standard in the evaluation of treatment results of patients who have undergone cardiac surgery [2].

Patients with cardiovascular disease make up a significant percentage of the patients of family physicians; cardiovascular disease accounts for nearly half of all deaths in Poland, and is the most frequent cause of death [3]. Cardiac surgery has become increasingly common in Poland over the last decade [4], and is a recognized and effective treatment method that results in significant improvements in quality of life and life span [5]. However, as studies show, the patients who have undergone cardiac surgery often ex- perience distress, which may have an adverse influence not only on their social functioning and job performance, but also on their health status, as measured by objective indicators [6]. The association of depression and anxiety with treatment results is most evident in cases of cardiovascular disease $[2,7]$. Moreover, as combined medical and economic research has shown, the depression and anxiety that accompany a chronic disease can lead to an increased number of diagnostic tests and consultations, which may lead to as much as a doubling of treatment costs [8]. This is why it is necessary to conduct research which would allow an improved understanding of the relations between chronic diseases (including heart disease) and depression and anxiety $[7,9]$. The diagnosis of concomitant mental disorders is indispensable in care optimization [8]. A number of studies have been devoted to the depression and cardiovascular disease concomitance, in spite of the fact that it is anxiety rather than depression that is more closely associated with cardiovascular incidence $[10,11]$.

The authors' own clinical experience, as well as numerous other studies, shows that patients' anxiety levels are highest before cardiac surgery, and then decrease in most cases [12]. However, as many as $40 \%$ of patients who have 
undergone cardiac surgery may struggle with intense anxiety symptoms [6]. Anxiety after cardiac surgery is associated with an increased number of hospitalizations, adverse treatment outcomes, and even death from cardiovascular factors [11]. Anxiety is also considered not only to be a risk factor for cardiovascular disease [13], but also a risk factor for cardiac mortality $[2,7]$.

\section{Objectives}

This study aimed to evaluate anxiety levels among patients who had undergone cardiac surgery and to exploring the correlations between anxiety and depression and subjective health status.

\section{Material and methods}

The research group consisted of 70 patients (of which 48 were men). The mean age was 65.9 years $( \pm 8.5$; range: 43-84). Most patients (70\%) had undergone off-pump coronary artery bypass grafting (OPCABG). Other procedures included aortic valve replacement (AVR) and mitral valve replacement (MVR), as well as combined procedures such as valve replacement with coronary artery bypass grafting $(A \vee R / M V R+C A B G)$. A description of the test group is presented in Table 1.

\begin{tabular}{|l|l|}
\hline \multicolumn{2}{|l|}{ Table 1. Details of the test group $(\boldsymbol{n}=\mathbf{7 0})$} \\
\hline $\begin{array}{l}\text { Gender, } n(\%) \\
\text { Female } \\
\text { Male }\end{array}$ & $22(31.4)$ \\
\hline Age average (SD)* & $48(68.6)$ \\
\hline Procedure, $n(\%)$ & $65.9(8.5)$ \\
OPCABG & \\
AVR/MVR & $49(70)$ \\
AVR/MVR + CABG & $9(12.9)$ \\
Off-pump, $n(\%)$ & $12(17.1)$ \\
\hline
\end{tabular}

$*$ SD - standard deviation.

The study was conducted during a routine cardiac surgery consultation three months after the operation. The Hospital Anxiety and Depression Scale (HADS) was used; this scale consists of 14 questions, of which seven deal with anxiety symptoms and the other seven with symptoms of depression. The assessment is made by summing the results separately for each subscale (anxiety and depression). The score ranges from 0 to 21 points; a score of 7 or less denotes the norm, a score of 8 to 10 indicates possible disorders, and a score of 11 or more denotes probable depression or anxiety [14]. A question regarding suicidal thoughts was also included in the scale. Patients were also asked to assess the improvement or worsening of their health following surgery using four-point Likert scale. The Visual Analogue Scale (VAS) was used to assess subjective health status. Patients assessed their health status according to a ten-point scale, with 0 meaning "My health status is very poor" and 10 indicating "My health status is excellent". The project obtained the consent of the Independent Bioethics Committee for Scientific Research at the Medical University of Gdansk.

\section{Statistical analysis}

Statistical calculations were of the performed by means of Statistica 12 (StatSoft). The normality of the distribution tested variables was assessed by means of the Shapiro-Wilk test. The normally distributed variable (age) is presented as mean with standard deviation (SD), whereas the variables lacking normal distribution (anxiety, depression, self-assessed general health status, subjective postsurgical health improvement) are presented as medians with minimum and maximum values. Spearman's correlation coefficient was used to evaluate correlations between the studied variables. The groups formed on the basis of ordinal and quantitative variables were compared using the Mann-Whitney U-test, Student's $t$-test, or the Kruskal-Wallis ANOVA test. The groups formed on the basis of qualitative variables were compared using Pearson's chi-square test. The assumed significance level was $p \leq 0.05$.

\section{Results}

An increased level of anxiety (a score of more than 7 on the HADS scale) was noted in 23 patients from the tested group, whereas 12 patients $(17.1 \%)$ showed increased levels of depression; 13 patients from the whole group (18.6\%) indicated that they had had suicidal thoughts. The anxiety level median was 6 points and the depression median was 4.5 points. 69 patients $(98.6 \%)$ stated that they had experienced different degrees of postsurgical health improvement. The results are presented in Table 2.

Table 2. Anxiety and depression levels and health status selfassessment in the test group $(n=70)$

\begin{tabular}{|l|l|}
\hline Tested variable & $n(\%)$ \\
\hline Level of anxiety above the norm & $23(32.9)$ \\
\hline Depression of anxiety above the norm & $12(17.1)$ \\
\hline Suicidal thoughts & $13(18.6)$ \\
\hline Subjective postsurgical health improvement & $69(98.6)$ \\
\hline & $\begin{array}{l}\text { median } \\
(\mathbf{m i n}-\mathbf{m a x})\end{array}$ \\
\hline Anxiety (HADS) & $6(0-15)$ \\
\hline Depression (HADS) & $4.5(1-15)$ \\
\hline Self-assessment of general health status & $6(1-10)$ \\
\hline Subjective postsurgical health improvement & $2(0-3)$ \\
\hline
\end{tabular}

Significantly higher anxiety levels were noted among the patients who stated that they had suffered from suicidal thoughts. No significant correlations between gender and type of surgery, including on/off pump surgery, were noted. The results are presented in Table 3.

\begin{tabular}{|c|c|c|}
\hline & Anxiety level & $p$ \\
\hline $\begin{array}{l}\text { Women* } \\
\text { Men }\end{array}$ & $\begin{array}{l}5(1-15) \\
6(0-14)\end{array}$ & 0.808 \\
\hline $\begin{array}{l}\text { Suicidal thoughts** } \\
\text { Yes } \\
\text { No }\end{array}$ & $\begin{array}{l}8.85(4.28) \\
5.33(3.33)\end{array}$ & $0.002^{\#}$ \\
\hline $\begin{array}{l}\text { Surgery type** } \\
\text { OPCABG } \\
\text { AVR/MVR } \\
\text { AVR/MVR + CABG }\end{array}$ & $\begin{array}{l}6.35(3.97) \\
6.22(3.49) \\
4.33(2.61) \\
\end{array}$ & 0.307 \\
\hline $\begin{array}{l}\text { Off-pump surgery** } \\
\text { Non-off-pump surgery }\end{array}$ & $\begin{array}{l}5.14(3.09) \\
6.35(3.97)\end{array}$ & 0.903 \\
\hline
\end{tabular}

* - variables are presented as medians (min-max); ** - variables presented as means with standard deviations (SDs); \# - statistically significant differences according to Student's $t$-test $(p \leq 0.05)$. 
The next stage in the study was devoted to establishing the relations between the tested variables. A statistically significant positive correlation was found between anxiety level and depression level. There was a significant negative correlation between anxiety level and subjective assessment of the general health status and the subjective assessment of postsurgical health improvement - that is, the perception of the surgery's effectiveness. No significant relation between anxiety levels and the age of patients was noted. The results are presented in Table 4

\begin{tabular}{|l|l|l|}
\hline \multicolumn{3}{|l|}{$\begin{array}{l}\text { Table 4. Relation between anxiety level, depression level, } \\
\text { and health status self-assessment }\end{array}$} \\
\hline & Anxiety level* & $p$ \\
\hline Age & 0.161 & 0.182 \\
\hline Depression & 0.673 & $0.000^{* *}$ \\
\hline Health status self-assessment & -2.334 & $0.023^{* *}$ \\
\hline $\begin{array}{l}\text { Perceived postsurgical health } \\
\text { improvement }\end{array}$ & -3.301 & $0.002^{* *}$ \\
\hline
\end{tabular}

* - Spearman's correlation coefficient; ** - statistically significant correlations, $p \leq 0.05$.

\section{Discussion}

This study aimed to assess anxiety levels in patients who had undergone cardiac surgery. The general level of anxiety was not high in the tested group; however, the study permitted us to identify an increased level of anxiety in a significant percentage of patients (32\%). Similar levels of both anxiety and depression were noted by Sveinsdóttir and Ingadóttir [6], but the percentage of patients with considerable distress was lower. The reason for this discrepancy may lie in the different gender distribution in the two studies (our study had a higher percentage of women), as well as in the different time span between the surgery and the tests (four weeks versus three months). Rymaszewska et al. noted more similar percentages of patients with considerable levels of anxiety $(32 \%)$ and depression (26\%) following the CABG procedure [15]. Our own earlier research [16], as well as the works of other authors $[6,15]$, confirm our present results, which show that anxiety occurs more frequently than symptoms of intense depression. The percentage of patients with intense anxiety or depression was lower than in primary health care patients suffering from cardiovascular diseases; it turned out that up to $55 \%$ of these patients may have developed concomitant mental disorders [9]. These discrepancies arise from the methodological differences between the two studies; it may also be possible that past surgical treatment that favorably affected patients' health and physical condition also resulted in the improvement of their psychological state. Such dependencies in patients who had undergone cardiac surgery have been revealed by other authors' re- search [6]. This hypothesis may receive further confirmation from the correlation observed between the intensity of anxiety and health self-assessment and the subjective postsurgical health assessment; patients with higher anxiety levels tended to assess their health status as worse. This result has practical relevance: patients' low subjective assessment of health status may signal that it is necessary to determine whether the patient has developed any mental disorders that require therapeutic intervention.

Our research also showed considerable concomitance of anxiety and depression symptoms. Our results seem to be consistent with the conclusions of Scott et al., who, having tested more than 42.000 patients, discovered that the concomitance of anxiety and depression was highly prevalent. They also found that the combination of the two disorders had a greater negative influence on patients' health status than did each of them separately [7]. It has also been pointed out that patients with intense anxiety symptoms may belong to a depression risk group, and that anxiety screening may prove useful in identifying patients with post-heartattack depression. It should also be stressed that, as research shows, it is the anxiety that constitutes the main symptom of depressive disorder among these patients' [11].

Our research also showed that a significant percentage of patients had suffered from suicidal thoughts. No data on this vital issue were available to us in the literature on patients who had undergone cardiac surgery. Shemesh et al. [17] indicate that around $12 \%$ of cardiovascular patients may require deeper evaluation with respect to suicidal thoughts or intentions. The authors of one article on heartdisease-related depression insist that clinicians should not hesitate to ask their patients about their sense of hopelessness or suicidal thoughts [18]. The guidelines on diagnosing and treating cardiovascular patients also recommend screening for suicidal ideation [19].

The fact that indicators of the patients' clinical state were not taken into account constitutes a limitation of our presented study. Nevertheless, our study indicates the importance of the issue of distress in post-cardiac-surgery patients; the search for concomitant factors, including clinical factors, is likely to become the topic of further, more extensive investigations. Early recognition of the symptoms of anxiety or depression by a family doctor or a cardiologist can permit suitable treatment. Pharmacotherapy, psychotherapy, and education have proved effective for cardiovascular patients and for patients who have undergone CABG procedures $[6$, $15,20]$.

\section{Conclusions}

1. Increased levels of anxiety were observed in a significant percentage of patients who had undergone cardiac surgery.

2. Increased levels of anxiety are concomitant with depression, suicidal thoughts, and lower subjective assessment of health status.

3. Health status assessment after cardiac surgery should also include mental health evaluation.

\section{References}

1. Rumsfeld JS, Alexander KP, Goff DC. Cardiovascular Health: the importance of measuring patient-reported health status. A scientific from the American Heart Association. Circulation 2013; 127(22): 2233-2249.

2. Cserep Z, Losoncz E, Toth R, et al. Self-rated health is associated with the length of stay at the intensive care unit and hospital following cardiac surgery. BMC Cardiovasc Disord 2014; 14(1): 171, doi: 10.1186/1471-2261-14-171. 
3. Strzelecki Z, Szymborski J, eds. Zachorowalność i umieralność na choroby układu krążenia a sytuacja demograficzna Polski. Warszawa: Rządowa Rada Ludnościowa; 2015.

4. Rejestr głównych typów operacji kardiochirurgicznych w 2015 r. w poszczególnych ośrodkach w Polsce. Kardiochir Torakochir Pol 2016; 13(2): 185-188.

5. Hawkes AL, Nowak M, Bidstrup B, et al. Outcomes of coronary artery bypass graft surgery. Vasc Health Risk Manag 2006; 2(4): 477-484.

6. Sveinsdóttir $\mathrm{H}$, Ingadóttir B. Predictors of psychological distress in patients at home following cardiac surgery: an explorative panel study. Eur J Cardiovasc Nurs 2012; 11(3): 339-348.

7. Scott KM, Bruffaerts R, Tsang A, et al. Depression-anxiety relationships with chronic physical conditions: results from the World Mental Health Surveys. J Affect Disord 2007; 103(1-3): 113-120.

8. Katon W, Lin EHB, Kroenke K. The association of depression and anxiety with medical symptom burden in patients with chronic medical illness. Gen Hosp Psychiatry 2007; 29(2): 147-155.

9. Gilli M, Comas A, Garcia-Garcia M, et al. Comorbidity between common mental disorders and chronic somatic diseases in primary care. Gen Hosp Psychiatry 2010; 32(3): 240-245.

10. Roest AM, Zuidersma M, de Jonge P. Myocardial infarction and generalized anxiety disorder: 10-year follow-up. Br J Psychiatry 2012; 200(4): 324-329.

11. Roy-Byrne PP, Davidson K, Kessler RC, et al. Anxiety disorders and comorbid medical illness. Gen Hosp Psychiatry 2008; 30(3): 208-225.

12. Nowicka-Sauer K, Jarmoszewicz K, Szyndler K, et al. Jak wyrazić ból i chorobę? Wykorzystanie rysunku do oceny percepcji bólu i choroby wśród pacjentów oczekujących na zabieg pomostowania aortalno-wieńcowego. Raport wstępny. Forum Med Rodz 2015; 9(5): 288-290.

13. Scherrer JF, Chrusciel T, Zeringue A, et al. Anxiety disorders increase risk for incident myocardial infarction in depressed and non-depressed Veterans Administration patients. Am Heart J 2010; 159(9): 772-779.

14. Zigmond AS, Snaith RP. The hospital anxiety and depression scale. Acta Psychiatr Scand 1983; 67(6): 361-370.

15. Rymaszewska J, Kiejna A, Hadryś T. Depression and anxiety in coronary artery bypass grafting patients. Eur Psychiatry 2003; 18(4): 155-160.

16. Nowicka-Sauer K, Pietrzykowska M, Staśkiewicz I, et al. Lęk u pacjentów z chorobami przewlekłymi: istotny a marginalizowany problem. Fam Med Prim Care Rev 2015; 17(2): 120-123.

17. Shemesh E, Annunziato RA, Rubinstein D, et al. Screening for depression and suicidality in patients with cardiovascular illnesses. Am J Cardiol 2009; 104(9): 1194-1197.

18. Kemp DE, Malhotra S, Franco KN, et al. Heart disease and depression: don't ignore the relationship. Cleveland Clinic J Med 2003; 70(9): 745-761.

19. Tully PJ, Baker RA. Depression, anxiety, and cardiac morbidity outcomes after coronary artery bypass surgery: a contemporary and practical review. J Geriatr Cardiol 2012; 9(2): 197-208.

20. Freedland KE, Skala JA, Carney RM, et al. Treatment of Depression After Coronary Artery Bypass Surgery: A Randomized Controlled Trial FREE. Arch Gen Psychiatry 2009; 66(4): 387-396, doi:10.1001/archgenpsychiatry.2009.7.

Address for correspondence:

Katarzyna Nowicka-Sauer, MD, PhD

Katedra Medycyny Rodzinnej GUM

ul. Dębinki 2

80-211 Gdańsk

Polska

Tel.: +48 58 349-15-79

E-mail:kpsauer@gumed.edu.pl

Received: 31.03.2016

Revised: 14.04.2016

Accepted: 22.04.2016 